\title{
OBITUARIES
}

\section{Dennis James Pudifin}

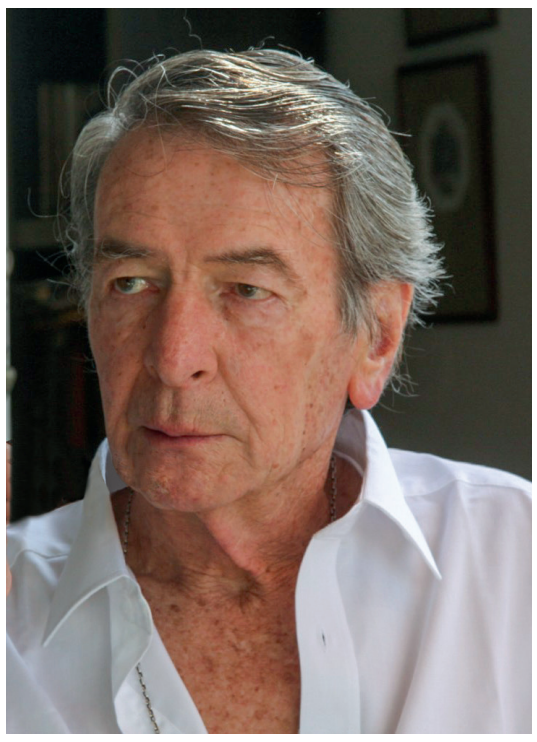

Prof. Dennis Pudifin passed away on 3 December 2013. He was born on 13 May 1934.

Dennis qualified from the University of Cape Town in 1957 as a medical doctor. He did his internship at Edendale Hospital in Pietermaritzburg and then trained in the same hospital under Dr John Cosnett, a well-known physician who was skilled in clinical medicine and whose obituary Dennis provided a few months ago. Dennis obtained his fellowship in internal medicine from the Colleges of Medicine of South Africa and then joined the Department of Medicine at King Edward VIII Hospital, Durban, as a consultant/lecturer. In 1980 he was appointed Professor of Medicine and Deputy Head of the Department of Medicine at the University of Natal. His particular interests were immunology, AIDS, clinical medicine and teaching. He spent a year at the Radcliffe Infirmary training in immunology, and published valuable research in that field with June Duursma. He was an active member of the British Society of Immunology and the South African Society of Immunology, of which he was president in 1988, and he was elected a fellow of the Royal College of Physicians of London in 1979. In 1994 he reached retiring age, but he continued working as a physician and as Emeritus Professor until just before his death. In spite of a terminal illness, he remained passionate about teaching students.

Medicine consists of two components, the scientific aspect and the humane aspect. In spite of scientific and technological advances, the doctor of today does not enjoy the same respect as in the past. Before the days of antibiotics the general practitioner in many a small town made house calls. He or she had very few effective drugs, yet was a highly respected member of the community. How was this respect earned, and why is it disappearing? The doctor cared for the patient and the family. He comforted the patient, and if the patient died, he comforted the family. He applied ethical principles to his practice: do no harm to the patient (primum non nocere), practise beneficence, refrain from maleficence, and maintain patient confidentiality. Respect in life is earned, not endowed because of position.

Dennis had a strong ethical code, and was devoted to the Medical School and the Department of Medicine. He cared for his patients, and enjoyed teaching students. This is a dying breed today. I am deeply indebted to him for his loyalty, friendship and advice while he served as my deputy.

Dennis's first wife died, and his son died tragically on a yacht in the Indian Ocean. His daughter Collett, from his first wife, settled in Australia. He leaves his second wife Jenny and their daughter Sarah.

Like Chaucer's 'veray parfit gentil knight', Dennis was a gentleman. I would like to end by quoting Mark Anthony's tribute to the dead Brutus in Shakespeare's Julius Caesar:

'His life was gentle, and the elements

So mixed in him that nature might stand up And say to all the world "This was a man".

\section{Y K Seedat}

Emeritus Professor of Medicine, Nelson $R$ Mandela School of Medicine, University of KwaZulu-Natal, Durban, South Africa seedaty1@gmail.com 